\title{
Mapeamento de áreas aluvionares no semiárido brasileiro por meio de dados colaterais e imagens orbitais
}

\author{
Helio L. Lopes ${ }^{1}$, Jaime J. da S. P. Cabral'2, \\ José C. de Araújo Filho ${ }^{3} \&$ Suzana M. G. L. Montenegro ${ }^{2}$
}

\begin{abstract}
RESUMO
A região semiárida do Brasil possui grande potencial para armazenamento de água em áreas aluvionares, podendo potencializar a pequena agricultura. Verifica-se a necessidade de uma metodologia para mapeamento dessas áreas, com o objetivo de futuros estudos in loco para implantação de barragens subterrâneas e manejo correto dos solos aluvionares. Neste sentido, objetivou-se a aplicação de imagens Landsat- Mapeador Temático 5 em conjunto com dados colaterais, como a rede de drenagem, mapa de classes de solo e mapa de relevo para auxiliar na classificação de terraços aluviais. Teve-se, como área de estudo, a bacia do Rio Pajeú, no sertão do estado de Pernambuco. Buscou-se também, por meio de dados SRTM (Shuttle Radar Topography Mission), a avaliação topográfica das áreas classificadas. Verifica-se que a utilização única de dados orbitais traz classificação incongruente mas com a inserção de dados colaterais é possível obter melhores resultados na classificação. A rede de drenagem é fundamental no mascaramento de classificações espúrias. Quando procede à análise topográfica por meio de dados do SRTM das áreas classificadas como terraços aluvionares, observa-se a inconsistência desses dados.
\end{abstract}

Palavras-chave: solos aluviais, classificação supervisionada, sensoriamento remoto, relevo

\section{Mapping alluvial areas in semi-arid region of Brazil through collateral data and satellite images}

\begin{abstract}
The semi-arid region of Brazil has great potential for storing water in alluvial areas, and may give support to small-scale family farming. There is a need to establish a methodology for mapping these areas with the objective of future studies to implement underground dams and suitable management of the soils that occur on alluvial terraces. In this way, the aim of this study was to apply Landsat-Thematic Mapper images together with collateral data such as the drainage network, map of soil classes and elevation data to assist in the classification of alluvial terraces. The study area was Pajeú River basin located in the 'Caatinga' ecosystem of the Pernambuco state. Topographic assessment of the alluvial areas was done by using SRTM (Shuttle Radar Topography Mission) data. It was found that the single use of orbital data brings incongruous classification, but with the inclusion of collateral data it was possible to obtain better results in classification. The drainage network was also important in masking the spurious classification. The analysis of the topography of the classified areas was inadequate using SRTM data.
\end{abstract}

Key words: alluvial soils, supervised classification, remote sensing, relief

'Engenharia Agrícola e Ambiental/UNIVASF. CEP 56304-205, Petrolina, PE. (In memoriam)

${ }^{2}$ Departamento de Engenharia Civil/UFPE. Av. Acad. Hélio Ramos, s/n. Cidade Universitária, CEP 50740-550, Recife, PE. Fone: (81) $2126-8223$. E-mail: jcabral@ufpe.br; suzanam@ufpe.br

${ }^{3}$ Embrapa Solos. Rua Antônio Falcão, 402, Boa Viagem, CEP 51020-240, Recife, PE. Fone: (81) 3325-0231. E-mail: coelhoembrapa@gmail.com 


\section{INTRODUÇÃO}

No Nordeste do Brasil existe a dificuldade de armazenamento de água das chuvas. Um dos principais fatores é sua formação geológica que compreende cerca de $55 \%$ da área com rochas cristalinas e $45 \%$ com predominância de formações sedimentares (Silva et al., 1993). As rochas sedimentares possibilitam o armazenamento de água no subsolo cessando sua perda por evaporação e desta forma permitem sua utilização em momentos futuros.

Os terraços aluvionares são formados em ambientes com relevos variados. Podem ocorrer entre relevos íngremes com gradiente baixo da linha de drenagem, resultandonuma redução da força da corrente diminuindo, consequentemente, a habilidade do curso d'água em carrear os sedimentos maiores (Hardgrove et al., 2009). Nos ambientes áridos a ocorrência de eventos pluviométricos em períodos curtos e geralmente intensos, pode potencializar as características de erosão. Assim, os sedimentos erodidos são depositados em locais com topografia favorável a cada evento chuvoso, que é um fenômeno comumente chamado gerações múltiplas de superfícies aluvionais (Frankel \& Dolan, 2007). Em razão da importância desses sedimentos observa-se a necessidade de se estabelecer uma metodologia para seu mapeamento por meio de técnicas espaciais utilizando-se dados de imagens de satélite, fotografias aéreas, radar e GPS.

Oliveira et al. (2007) utilizaram imagens do satélite SPOT e dados espectrorradiométricos de campo para delimitar áreas aluvionares no estado do Ceará. Este mapeamento foi realizado por meio da classificação supervisionada através do método da distância mínima. No trabalho de Gillespie et al. (1984) foram utilizadas bandas multiespectrais no infravermelho termal para mapeamento de aluviões já que as bandas multiespectrais podem ser usadas para distinguir diferentes formações rochosas incluindo quartzitos, carbonatos, rochas vulcânicas e depósitos salinos (Mulder et al., 2011). Diferenças entre cores representando aluviões podem estar relacionadas às características de material como cascalho, idade e brilho. Gellispie et al. (1984) propuseram interpretação baseada em bandas termais, dados de campo, estudos espectroscópicos e mapas geológicos. Frankel \& Dolan (2007) mapearam leques aluvionares por meio de laser utilizando a técnica de rugosidade da superfície extraída de dados de topografia digital.

Técnicas de campo com inspeção e levantamento topográfico consomem tempo e são laboriosas e possuem limitação espacial; logo, são mais aplicadas para pequeno segmento de determinada unidade de aluvião (Frankel \& Dolan, 2007). Uma alternativa são as imagens de alta resolução e o mapeamento a Laser (conhecido como LiDAR - Light Detection and Ranging). Essas tecnologias têm renovado o interesse para caracterização quantitativa de tipos de terreno aluvial e coluvial (Glenn et al., 2006; Staley et al., 2006; Gaber et al., 2010; Frankel \& Dolan, 2007) porém apresentam custos elevados em relação às imagens de satélite de média resolução.

Amit et al. (1996) observaram, em aluviões, diferenças no grau de desenvolvimento do solo principalmente onde há maior gradiente. Muitos trabalhos de mapeamento de feições aluvionares são baseados comumente em análise visual e inspeção qualitativa de fotografias aéreas (Crouvi et al., 2006). Um dos principais métodos no mapeamento de cronossequências de superfícies aluvionares é por meio da combinação entre características da cronosequência analisadas em campo com o mapeamento utilizando foto aérea. A foto aérea, tanto colorida quanto a nível de cinza, pode ser analisada por interpretação visual de diferentes respostas espectrais (Crouvi et al., 2006).

Crouvi et al. (2006) sugerem, contudo, utilizar um método alternativo mais quantitativo e objetivo para mapear superfícies aluvionares, com base em análise espectral de dados de reflectância hiperespectral. Sensores hiperespectrais possuem alta resolução espacial e espectral que permitem medidas quantitativas de uma feição específica de absorção. No entanto, a refletância de superfícies aluvionares tem sido estudada utilizando-se, na maioria dos casos, sensores multiespectrais (Gillespie et al., 1984). Al-Juaidi et al. (2003) utilizaram imagens TM em conjunto com imagens IRS para mapear superfícies aluviais por meio de análise de componentes principais. Na metodologia desenvolvida por Gaber et al. (2010) foram empregados três tipos de dados de micro-ondas, ex. SRTM (Shulttle Radar Topography Mission)/MDE (Modelo Digital de Elevação) para extrair características do terreno e Radarsat-1 e PALSAR para fusão com Landsat e classificação textural de depósitos aluviais além de determinação da rugosidade da superfície. A fusão foi executada com dois grupos de dados, ex. Landsat e Radarsat-1 e Landsat e PALSAR. A classificação dos depósitos aluvionares foi checada em campo e classes individuais foram legendadas de acordo com o tipo de depósito aluvial, textura e declividade da superfície. No trabalho de Gaber et al. (2010) foi possível identificar áreas favoráveis para armazenamento e extração de recursos hídricos de subsuperfície, ao longo da bacia estudada.

Diante do exposto objetivou-se, neste estudo, espacializar áreas aluvionares na bacia do rio Pajeú, no Sertão Pernambucano, por meio da classificação semissupervisionada de imagens Landsat TM5 contando com o apoio de dados de altimetria, drenagem e mapas de solo. Os resultados produzidos neste estudo poderão subsidiar avaliações hidrogeológicas dos terraços aluvionais que são características fundamentais para implantação sustentável de barragens subterrâneas e para o desempenho da pequena agricultura no semiárido.

\section{Material e Métodos}

A área experimental para aplicação da metodologia está localizada no sertão pernambucano onde predomina a vegetação da caatinga hiperxerófila (Araújo Filho et al., 2000). Foi escolhida a bacia do rio Pajeú que se estende desde o sul até o norte da área central do estado (Figura 1). Esta bacia possui uma extensão de $16.760 \mathrm{~km}^{2}$ representando $17,02 \%$ da área do Estado de Pernambuco. O rio Pajeú percorre 347 $\mathrm{km}$ até desaguar no lago formado pela Barragem de Itaparica, no Rio São Francisco. Drena uma área predominantemente sobre rochas cristalinas pertencentes ao complexo GnáissicoMigmatítico e Migmatítico-Granitóide (Dantas, 1980).

Para seleção de amostras de treinamento na etapa de classificação semissupervisionada foram utilizadas três 


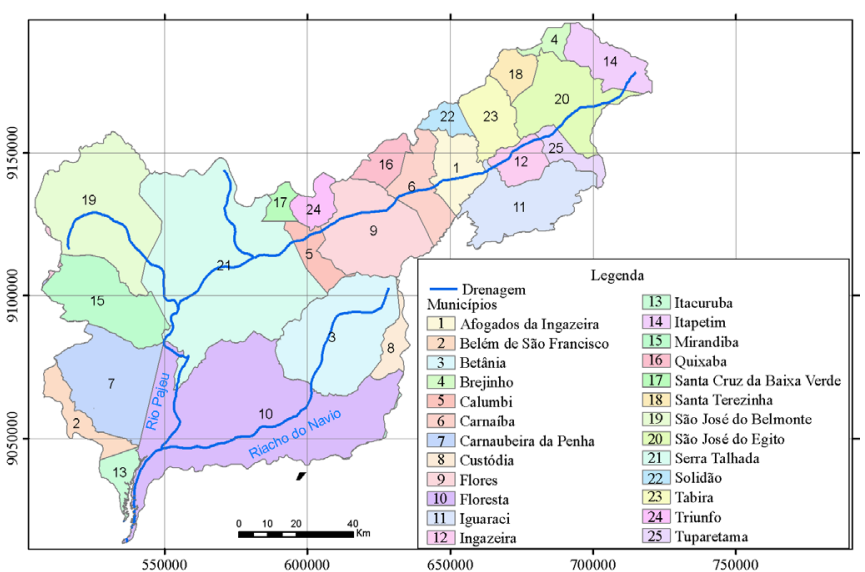

Figura 1. Bacia do Rio Pajeú com os afluentes principais e municípios pertencentes à bacia

camadas importantes para indicação das amostras. As camadas drenagem, classes de solos e relevo foram selecionadas com o objetivo de se escolher, visualmente, as regiões amostrais (Figura 2).

Para a classificação e espacialização das áreas aluvionais foram utilizadas imagens TM da data de 13/11/2009 e 20/11/2009, orbitas/pontos 215, 216/65, 216, 215/66. Essas imagens foram georreferenciadas utilizando-se o software Erdas 9.2 (Leica Geosystems) e em seguida foi preparado seu mosaico com o recorte no formato da bacia (Figura 3).

A partir de pontos conhecidos envolvendo classes de uso do solo, cobertura vegetal e áreas com terraços aluvionares, realizou-se o procedimento da classificação supervisionada na bacia. O método de classificação foi o MaxVer (máxima verossimilhança) disponível no Spring 5.1 (INPE) com probabilidade de $100 \%$. Buscou-se separar áreas com ocorrências principalmente de agricultura e solo expostos nas linhas de drenagem visando mapear áreas com ocorrência de prováveis terraços aluvionais.

A partir das camadas drenagem, solos e altimetria foram escolhidas as regiões de treinamento para o classificador. $\mathrm{O}$ classificador utilizado foi o MaxVer (máxima verossimilhança) disponível no Spring com o nível de probabilidade de 95\%.

\section{Resultados E Discussão}

Com a realização da classificação de uso e cobertura do solo por meio da classificação supervisionada, observou-se a ocorrência de pixel de áreas agrícolas em diversas classes de solo, gerando confusão com áreas agrícolas em áreas aluvionais. Sendo assim, três classes de agricultura e aluviões foram mapeadas (Figura 4). Diversos autores, como Jabbar \& Chen (2006) aplicaram técnicas de processamento digital de imagens para produzir informações sobre o uso e cobertura do solo baseados no método de máxima verossimilhança.

Verifica-se que as três classes de agricultura (Figura 4) podem ocorrer em aluviões e em diversas localidades na bacia, sobretudo ao longo das margens das linhas de drenagem. Essas três classes ocorrem em virtude de haver diferenças espectrais em função do uso agrícola da aluvião. As classes de agricultura correspondem a $21,93 \%$ da área da bacia (Tabela 1).

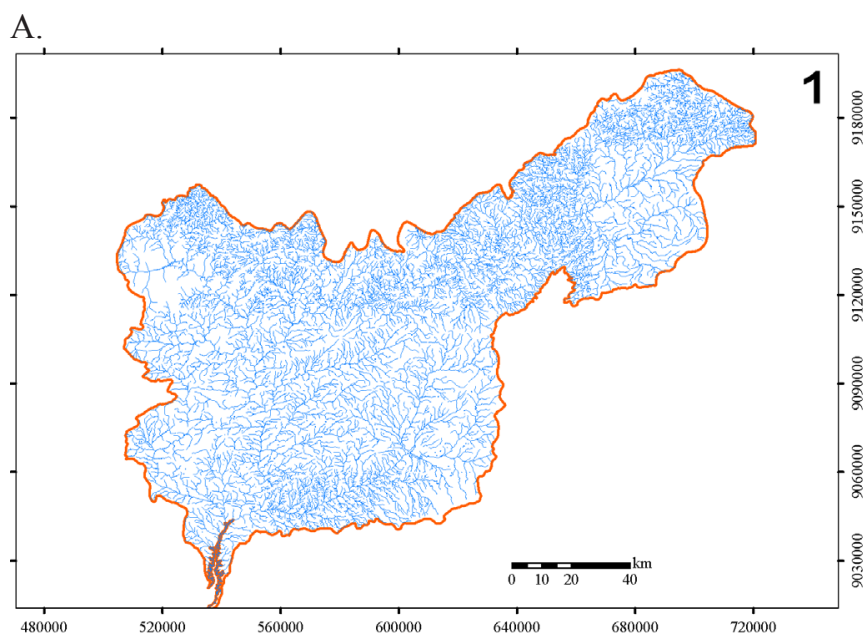

B.

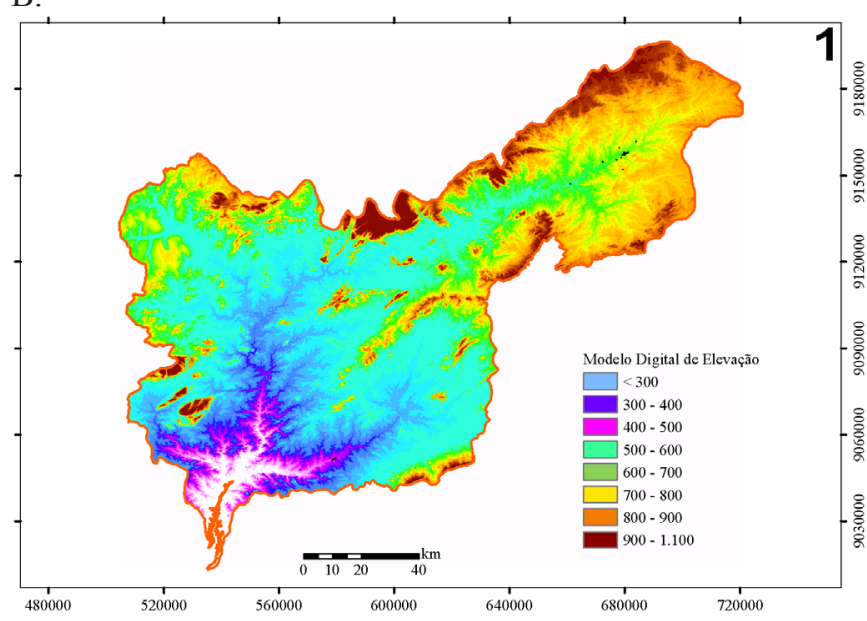

C.

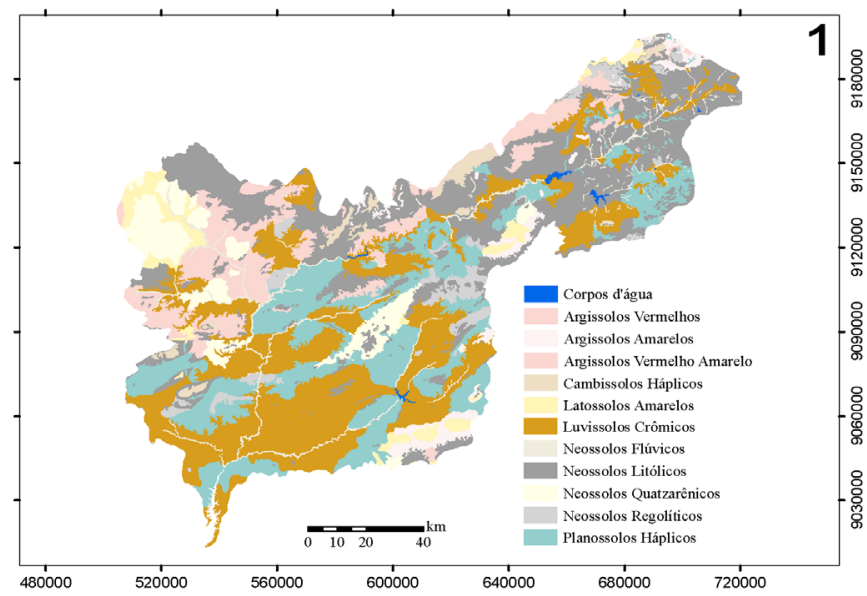

Figura 2. Camadas utilizadas da classificação semissupervisionada de aluviões na bacia do Rio Pajeú: A) Recorte da rede de drenagem na escala de 1:100.000; B) Classe de relevo gerada a partir do SRTM; C) Classes de solo na escala 1:100.000 do zoneamento do estado de Pernambuco (Araújo Filho et al., 2000; Silva et al., 2001)

Os valores correspondentes às áreas de agropecuária/ aluviões para as classes 1, 2 e 3 (Figura 4) foram 519,61, $1.410,59 \mathrm{e} 1.745,43 \mathrm{~km}^{2}$, respectivamente. Após a verificação de confusão nessas classes para a espacialização de aluviões buscou-se aplicar a classificação semiautomática, por meio 


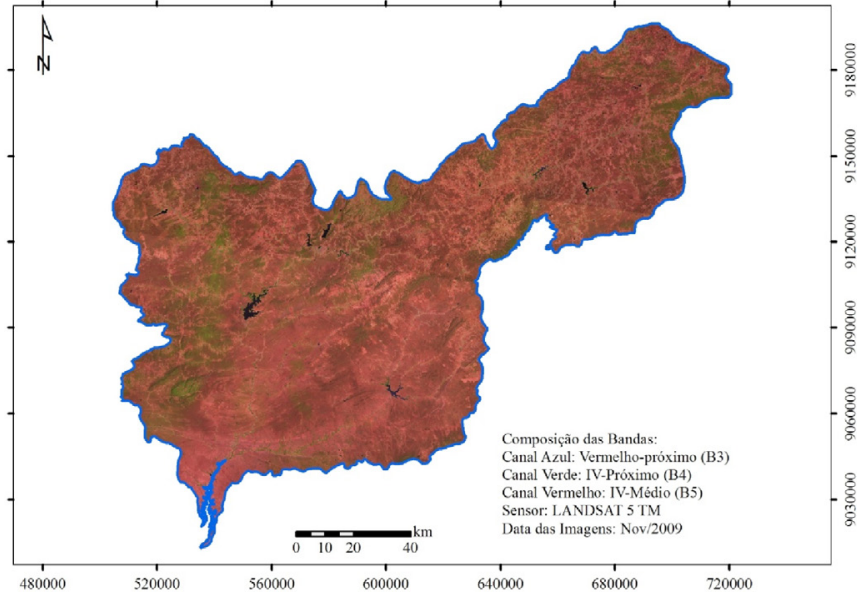

Figura 3. Mosaico das imagens Landsat TM usadas para o mapeamento de áreas aluvionais

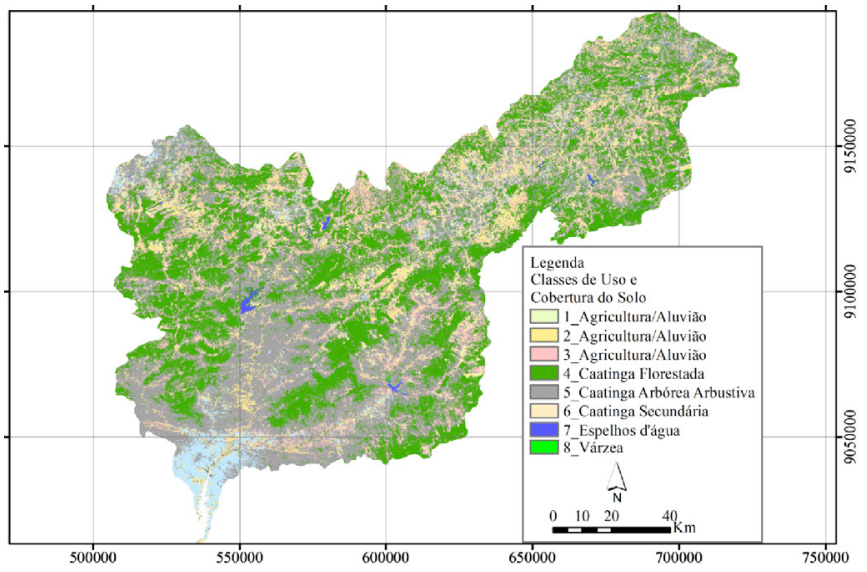

Figura 4. Classes de uso e cobertura do solo para a bacia do Pajeú

Tabela 1. Discriminação das classes de uso e cobertura do solo para bacia do Rio Pajeú

\begin{tabular}{lrr}
\hline Classes de uso e cobertura do solo & Área $\mathbf{( k m}^{\mathbf{2}}$ ) & \multicolumn{1}{c}{$\mathbf{( \% )}$} \\
Agropecuária/aluviões & $3.675,64$ & 21,93 \\
Caatinga florestada & $5.448,28$ & 32,51 \\
Caatinga arbórea arbustiva & $6.812,85$ & 40,65 \\
Caatinga secundária & 739,78 & 4,41 \\
Várzea & 2,24 & 0,01 \\
Espelhos d'água & 81,17 & 0,48 \\
\hline Total & 16.760 & 100,00 \\
\hline
\end{tabular}

das camadas de drenagem, relevo e solos. A combinação de modelos de elevação do terreno com dados espectrais pode melhorar a classificação de formas do terreno em paisagens complexas (Mulder et al., 2011). As amostras de treinamento foram escolhidas baseadas nessas camadas em regiões com ocorrência de linhas de drenagem e topografia mais plana, pois são ambientes nos quais normalmente ocorre acúmulo de sedimentos e solos aluvionais como os Neossolos Flúvicos e Cambissolos Flúvicos (Araújo Filho et al., 2000).

Além das características já citadas foram levadas em consideração as da imagem como a cor, textura, forma e tonalidade. Segundo Al-Juaidi et al. (2003) imagens Landsat TM têm sensibilidade na assinatura espectral para distinguir características da superfície representando potencial para mapear depósitos aluvionais e relacioná-los com a fonte litológica. A Figura 5 mostra o resultado da classificação pelo método da máxima verossimilhança; observa-se que, mesmo com os critérios adotados, ainda ocorreu classificação em regiões agrícolas fora de linhas de drenagem. O desempenho geral da classificação foi de $87,59 \%$; por conseguinte, a rejeição foi de $12,41 \%$ e a estatística kappa, de $46,69 \%$.

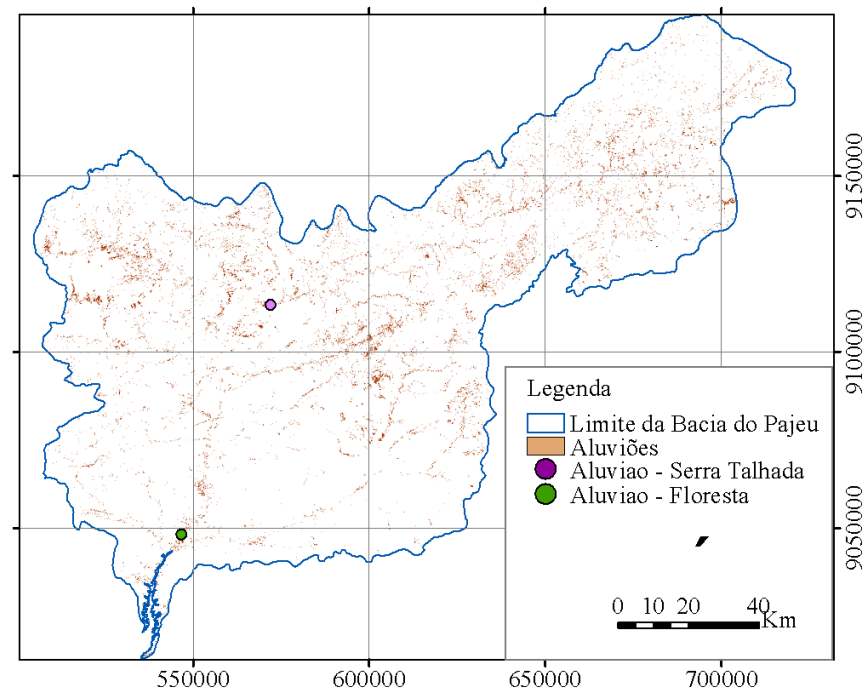

Figura 5. Dados resultantes da classificação semissupervisionada utilizando-se camadas auxiliares (linhas de drenagem, solo e relevo)

A área de classificação de aluvião foi de $399,54 \mathrm{~km}^{2}$ para todo o limite da bacia, o que corresponde a $2,38 \%$ porém ainda engloba áreas com falsa classificação, isto é, que não pertencem aos terraços aluvionares. Segundo Brito et al. (1999) há várias ocorrências de aluviões na região semiárida, que são feições geomorfólógicas de captação e armazenamento de água muito comuns nas bacias de base cristalina e que ocorrem principalmente nas linhas de drenagem. Em estudos realizados por Brivio et al. (2000) foram combinados hidrografia, dados altimétricos e processamento digital de imagens para delineamento de leques aluviais e outras feições geomorfológicas.

Para superar esta etapa de falsa classificação, a rede de drenagem principal foi utilizada como critério norteador visando separar áreas aluvionares e mascarar áreas inconsistentes. A partir das linhas de drenagem foi realizado um buffer de 500 $\mathrm{m}$ para os dois lados possibilitando a aplicação de uma rotina na linguagem LEGAL do Spring para geração de um plano de informação que contemplasse a classificação somente nessa região.

Após a aplicação do programa em LEGAL para retirar as áreas que representavam uso agrícola fora das áreas de "offset" das linhas de drenagem (Figura 6), o total de áreas classificadas em que se destacam os terraços aluvionais foi de $172,72 \mathrm{~km}^{2}$, que representa uma área de $1,03 \%$ da bacia do Pajeú. A Figura 7 mostra as prováveis áreas de aluviões após o mascaramento. Nesta Figura estão indicados dois pontos com terraços aluvionares que foram visitados para verificação da representatividade da metodologia de mapeamento proposta nesta pesquisa. 


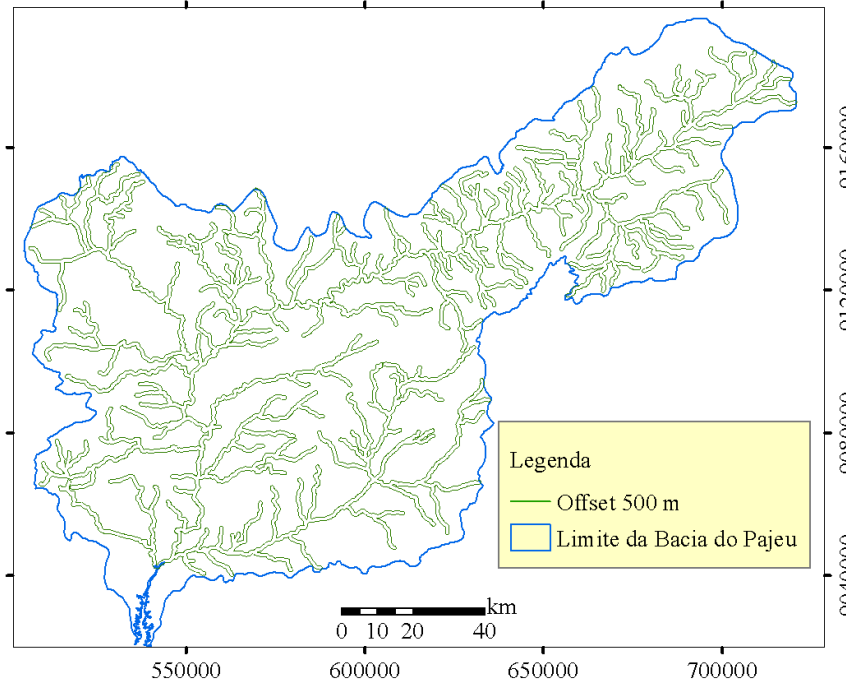

Figura 6. Mapa de distância gerado a partir da drenagem principal da bacia do Rio Pajeú visando identificar áreas com ocorrência de sedimentos aluvionais

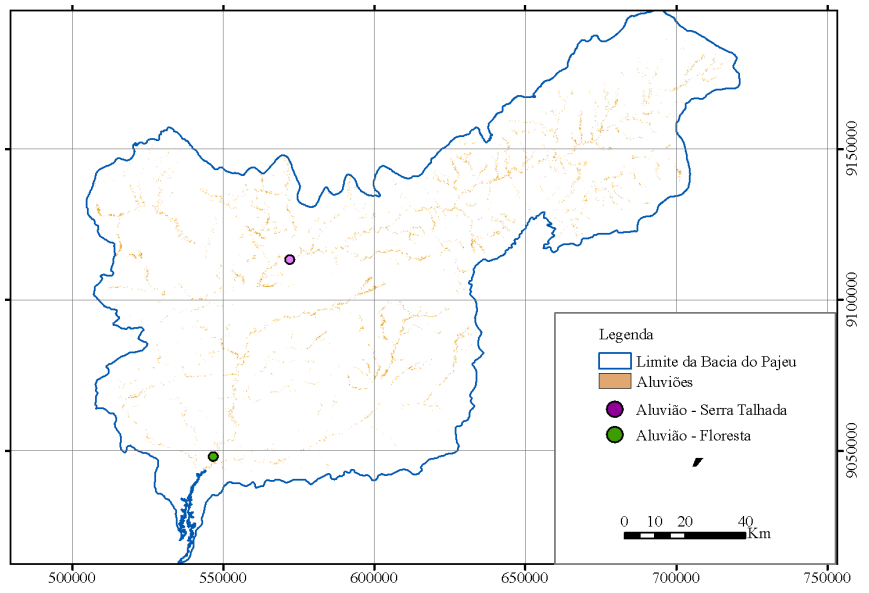

Figura 7. Regiões classificadas como domínio das aluviões considerando-se uma área de influência de 500 $\mathrm{m}$ para a direita e esquerda das principais drenagens na bacia do Rio Pajeú

Conforme a Figura 7 há maior probabilidade de ocorrência de aluviões nas regiões central e norte da bacia a qual pode estar relacionada com características pedológicas e topográficas.

$\mathrm{Na}$ Figura 8 se mostra a paisagem dessas duas áreas aluvionais indicadas na Figura 7.

Observa-se que nas regiões central e sul da bacia há predominância de solos rasos como, por exemplo, Luvissolos Crômicos e Neossolos Litólicos (Figura 2C), com gradiente variado, como se pode observar por meio de perfil do SRTM construído sobre a linha de drenagem (Figura 9)

Verifica-se que entre os pontos A e B há ocorrência de pontos topográficos com cotas menores e conforme este perfil podem estar dentro do erro do sensor considerando a tendência sistemática. Referido formato evidencia a ocorrência de áreas aluvionares, que para uma análise melhor há necessidade de levantamento topográfico em conjunto com observações pedológicas, conforme aplicado por Al-Juaidi et al. (2003). Brito et al. (1999) observam que, para o aproveitamento de terraços aluvionares em exploração agrícola por meio de barragens
A.

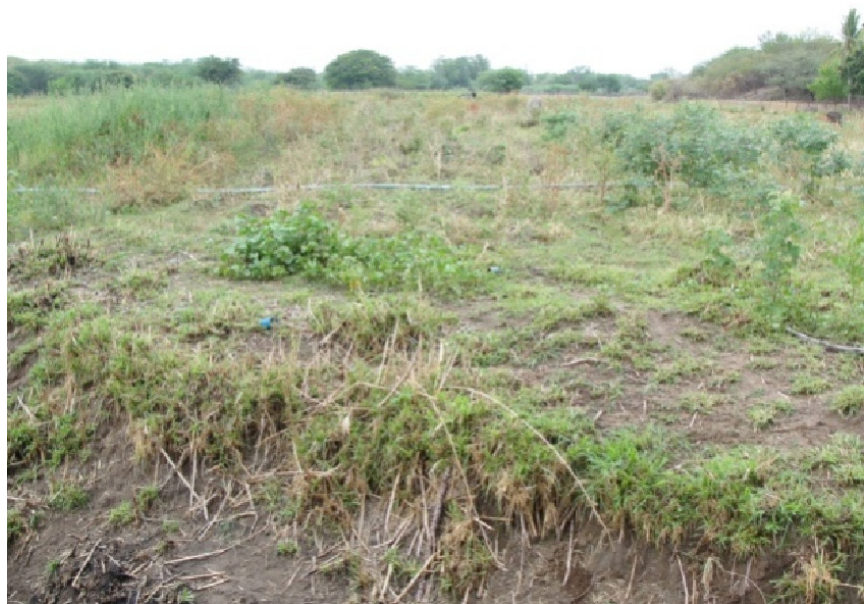

B.

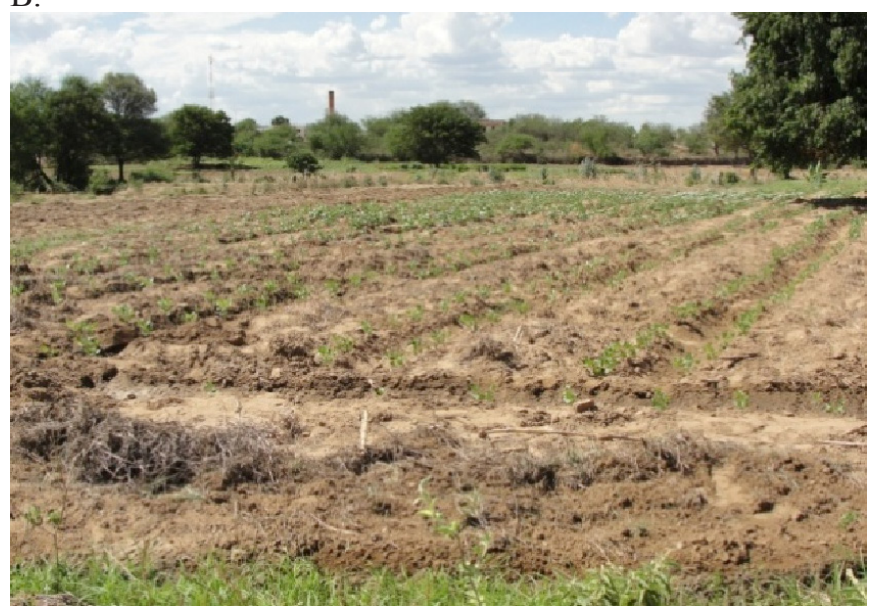

Figura 8. Terraços aluvionares na calha principal do Rio Pajeú. Área localizada no município de Serra TaIhada (A) e área localizada no município de Floresta (B)

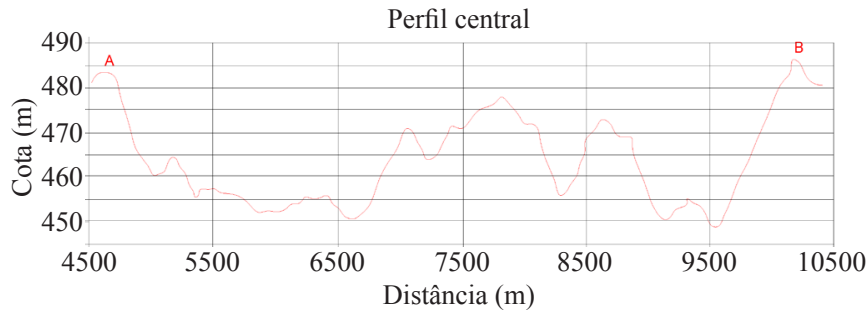

Figura 9. Perfil longitudinal do Rio Pajeú na região central da bacia

subterrâneas, os mesmos devem apresentar profundidade menor que $4 \mathrm{~m}$, textura média a grossa e declividade de até $4 \%$.

No estudo de um aluvião no estado de Pernambuco, Montenegro \& Montenegro (2006) afirmam que a declividade média do terraço aluvionar é de $0,3 \%$, que facilita o acúmulo de sedimentos e armazenamento de água. Desta forma, uma análise utilizando-se dados do sensor SRTM é tecnicamente inviável principalmente devido a ruídos. Por conseguinte, novos métodos mais precisos devem ser aplicados. Hohenthal et al. (2011) afirmam que durante as décadas recentes vem aumentando o uso de dados LiDAR em estudos fluviais, tendo potencial para mapeamento topográfico, que podem ser usados para acessar formas do terreno, dados geométricos de modelagem hidráulica e estimar planícies de inundação que, 
conforme Rayburg et al. (2009) possui precisão vertical e horizontal entre 8 e $11 \mathrm{~cm}$ e entre 2 e $3 \mathrm{~cm}$, respectivamente.

Em relação aos dados SRTM, Farr (2000) cita que possui uma precisão vertical absoluta de $16 \mathrm{~m}$ com precisão horizontal absoluta de $20 \mathrm{~m}$. Entretanto, para a região da caatinga foi encontrado erro de $1,8 \mathrm{~m}$ a $14 \mathrm{~m}$ a depender do porte da vegetação (Costa et al., 2010). Chagas et al. (2009) encontraram erros nos dados de elevação tanto do SRTM quanto do ASTER (Advanced Spaceborne Thermal Emission and Reflection Radiometer) comparados aos de cartas topográficas com equidistância de $20 \mathrm{~m}$ e verificaram que podem comprometer o estabelecimento das relações entre atributos do terreno e as condições locais de solos.

A Figura 10 mostra o perfil da região norte, em que se observou uma área com probabilidade de ocorrência de aluvião.

\section{A. Perfil longitudinal}

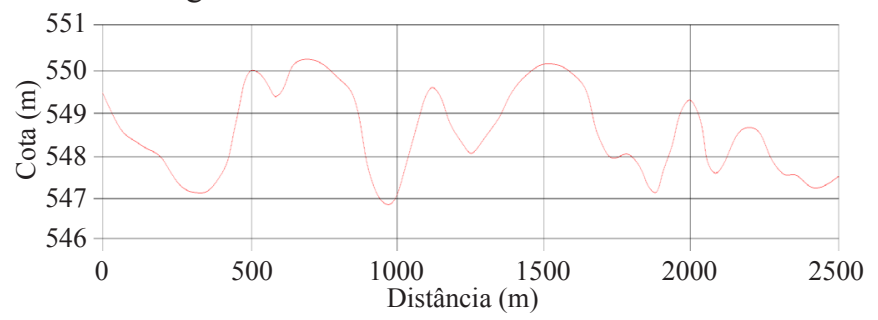

B. Perfil transversal

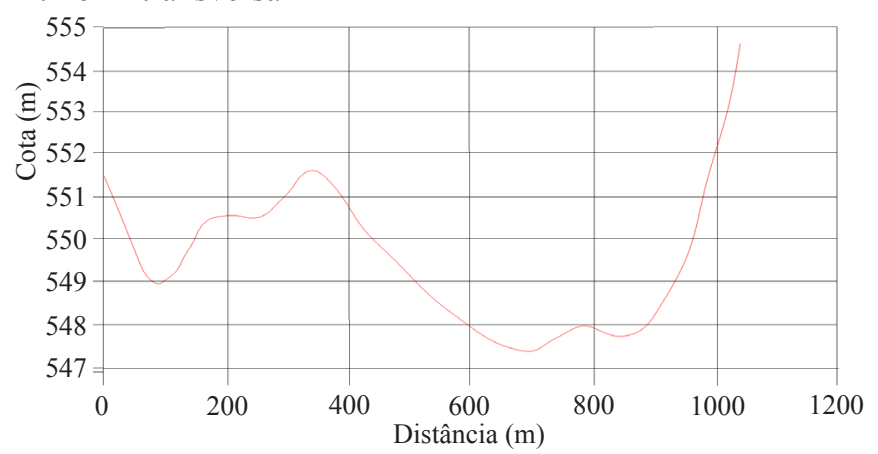

Figura 10. Representação da topografia em uma área mapeada com domínio de aluvião. A) Perfil longitudinal de uma linha de drenagem na parte norte da bacia do Pajeú, B) perfil transversal

Verifica-se que a morfologia transversal do perfil é mais côncava (Figura 10B) possibilitando acúmulo de sedimentos em eventos mais chuvosos enquanto o perfil longitudinal apresenta maior variação sendo a cota inicial de 549,53 m e final de 547,78 $\mathrm{m}$ para uma distância de $2.597,14 \mathrm{~m}$; porém, conforme visto neste perfil há bastante ocorrência de ruído, tornando-se tecnicamente incongruente a aplicação para avaliação de morfologia de terraços aluvionares devido à precisão do sensor SRTM.

Chagas et al. (2009) verificaram que as maiores discordâncias entre o MDE-SRTM e o MDE-CARTA ocorrem em seções longitudinais localizadas nas partes mais baixas e planas da área de estudo, observando que o número de depressões nos MDEs originados dos sensores é aproximadamente 5 vezes mais que o observado no MDE de cartas topográficas. Segundo Cavalli et al. (2008) atualmente o método mais preciso para coleta de dados de elevação para a geração de modelo digital de elevação, é o do LiDAR.
O comportamento visto nas Figuras 9 e 10 também foi observado em estudos realizados por Petersen et al. (2008) por meio de perfil de seção perpendicular à linha de drenagem, os quais observaram discrepâncias de 6-8 m em relação aos dados de referência de nível. Ludwig \& Schneider (2006) verificaram, em análise de dados SRTM para aplicação em modelagem hidrológica, por meio de visualização de perfil que as altitudes apresentavam maior ruído que os dados de validação, o que pode estar associado à vegetação e a outros objetos não topográficos. Assim, a rede de drenagem pode ser modelada incorretamente em áreas com abundância dessas feições. Karlsson \& Arnberg (2011) afirmam que um dos maiores erros nos dados do SRTM é a presença de vegetação.

Conforme observado, esta região possui coberturas múltiplas como: água, vegetação e solo exposto, que podem imprimir erros na derivação da superfície do terreno, a partir do SRTM, para análise topográfica de terraços aluvionares. No entanto, segundo Oliveira et al. (2010) o SRTM permite a caracterização morfométrica de bacias hidrográficas podendo auxiliar a gestão e o gerenciamento de recursos hídricos, porém Alcaraz et al. (2009) concluem que o uso de dados SRTM depende dos objetivos e da escala de trabalho.

\section{Conclusões}

1. A aplicação única de imagens de satélite (Landsat-TM) para mapeamento de aluvião no semiárido brasileiro implica na classificação incongruente de grandes áreas.

2. A associação de imagens de satélite (Landsat-TM) com dados colaterais como relevo, drenagem e solos em conjunto com técnicas de geoprocessamento, possibilita maior precisão na identificação cartográfica de áreas aluvionares.

3. Não é possível a geração de bons resultados através da análise detalhada da morfologia de prováveis aluviões por meio de dados SRTM devido principalmente ao ruído do sensor.

\section{Literatura Citada}

Alcaraz, S. A.; Sannier, C.; A. Vitorino, C. T.; Daniel, O. Comparison of methodologies for automatic and drainage networks for hidrographic basins. Revista Brasileira de Engenharia Agrícola e Ambiental, v.13, p.369-375, 2009.

Al-Juaidi, F.; Millington, A. C.; McLaren, S. J. Merged remotely sensed data for geomorphological investigations in deserts: examples from central Saudi Arabia. The Geographical Journal, v.169, p.117-130, 2003.

Amit, R.; Harrison, J. B. J.; Enzel, Y.; Porat, N. Soils as a tool for estimating ages of Quaternary. Catena, v.28, p.21-45, 1996.

Araújo Filho, J. C.; Burgos, N.; Lopes, O. F.; Silva, F. H. B. B.; Medeiros, L. A. R.; Mélo Filho, H. F. R.; Parahyba, R. B. V.; Cavalcanti, A. C.; Oliveira Neto, M. B.; Silva, F. B. R.; Leite, A. P.; Santos, J. C. P.; Sousa Neto, N. C.; Silva, A. B.; Luz, L. R. Q. P.; Lima, P. C.; Reis, R. M. G.; Barros, A. H. C. Levantamento de reconhecimento de baixa e média intensidade dos solos do estado de Pernambuco. Recife: Embrapa Solos/UEP Recife; Rio de Janeiro: Embrapa Solos, 2000. 252p. Boletim de Pesquisa, 11 
Brito, L. T. de L.; Silva, D. A. da; Cavalcanti, N. de B.; Anjos, J. B. dos; Rego, M. M. do. Alternativa tecnológica para aumentar a disponibilidade de água no semi-árido. Revista Brasileira de Engenharia Agrícola e Ambiental, v.3, p.111$115,1999$.

Brivio, P. A.; Pepe, M.; Tomasoni, R. Multispectral and multiscale remote sensing data for archaeological prospecting in an alpine alluvial plain. Journal of Cultural Heritage, v.1, p.155-164, 2000.

Cavalli, M.; Tarolli, P.; Marchi, L.; Fontana, G. D. The effectiveness of airborne LiDAR data in the recognition of channel-bed morphology. Catena, v.73, p.249-260, 2008.

Chagas, C. S.; Fernandes Filho, E. I.; Rocha, M. F.; Carvalho Júnior, W. de; Souza Neto, N. C. Avaliação de modelos digitais de elevação para aplicação em um mapeamento digital de solos. Revista Brasileira de Engenharia Agrícola e Ambiental, v.14, p.218-226, 2010.

Costa, C. A. G.; Teixeira, A. dos S.; Andrade, E. M. de; Lucena, A. M. P. de; Castro, M. A. H. de. Análise da influência vegetacional na altimetria dos dados SRTM em bacias hidrográficas no semiárido. Revista Ciência Agronômica, v.41, p.222-230, 2010.

Crouvi, O.; Ben-Dor, E.; Beyth, M.; Avigad, D.; Amit, R. Quantitative mapping of arid alluvial fan surfaces using field spectrometer and hyperspectral remote sensing. Remote Sensing of Environment, v.104, p.103-117, 2006.

Dantas, J. R. A. Mapa geológico do estado de Pernambuco. Recife: DNPM, 1980. 112p.

Farr, T. G. The shuttle radar topography mission. IEEEAerospace Conference, 2000, Manhattan Beach. Proceedings... Piscataway: IEEE Publications Orders, 2000. 63p.

Frankel, K. L.; Dolan, J. F. Characterizing arid region alluvial fan surface roughness with airborne laser swath mapping digital topographic data. Journal of Geophysical Research, v.112, p.1-14, 2007.

Gaber, A.; Koch, M.; El-Baz, F. Textural and compositional characterization of wadi feiran deposits, Sinai Peninsula, Egypt, using Radarsat-1, PALSAR, SRTM and ETM+ data. Remote Sensing, v.2, p.52-75, 2010.

Gillespie, A. R.; Kahle, A. B.; Palluconi, F. D. Mapping alluvial fans in Death Valley, California, using multichannel thermal infrared imagens. Geophysical Research Letters, v.11, p.1153-1156, 1984.

Glenn, N. F.; Streuker, D. R.; Chadwick, D. J.; Thackray, G. D.; Dorsch, S. J. Analysis of LiDAR-derived topographic information for characterizing and differentiating landslide morphology and activity. Geomorphology, v.73, p.131-148, 2006.

Hardgrove, C.; Moersch, J.; Whisner, S. Thermal imaging of alluvial fans: A new technique for remote classification of sedimentary features. Earth and Planetary Science Letters, v.285, p.124-130, 2009.

Hohenthal, J.; Alho, P.; Hyyppä, J.; Hyyppä, H. Laser scanning applications in fluvial studies. Progress in Physical Geography, v.35, p.782-809, 2011.
Jabbar, M. T.; Chen, X. Land degradation assessment with the aid of geo-information techniques. Earth Surface Processes and Landforms, v.31, p.777-784, 2006.

Karlsson, J. M.; Arnberg, W. Quality analysis of SRTM and HYDRO1K: A case study of flood inundation in Mozambique. International Journal of Remote Sensing, v.32, p.267-285, 2011.

Ludwig, R.; Schneider, P. Validation of digital elevation models from SRTM X-SAR for applications in hydrologic modeling. ISPRS Journal of Photogrammetry \& Remote Sensing, v.60, p.339-358, 2006.

Montenegro, A. A. A.; Montenegro, S. M. G. L. Variabilidade espacial de classes de textura, salinidade e condutividade hidráulica de solos em planície aluvial. Revista Brasileira de Engenharia Agrícola e Ambiental, v.10, p.30-37, 2006.

Mulder, V. L.; Bruin, S. de; Schaepman, M. E.; Mayr, T. R. The use of remote sensing in soil and terrain mapping - A review. Geoderma, v.162, p.1-19, 2011.

Oliveira, F. de A. J. de; Martins, E. S. P. R.; Möbus, G.; Kosuth, P. Metodologia para o mapeamento de aluviões a partir de imagem satélite SPOT no semiárido cearense - Um de estudo de caso. In: Simpósio Brasileiro de Sensoriamento Remoto, 13, 2007, Florianópolis Anais... Florianópolis: INPE, 2007, p.3491-3498.

Oliveira, P. T. S. de; Alves Sobrinho. T.; Steffen, J. L.; Rodrigues, D. B. B. Caracterização morfométrica de bacias através de dados SRTM hidrográficas. Revista Brasileira de Engenharia Agrícola e Ambiental, v.14, p.819-825, 2010.

Petersen, G.; Sutcliffe, J. V.; Fohrer, N. Morphological analysis of the Sudd region using land survey and remote sensing data. Earth Surface Processes and Landforms, v.33, p.17091720, 2008.

Rayburg, S.; Thoms, M.; Neave, M. A comparison of digital elevation models generated from different data sources. Geomorphology, v.106, p.261-270, 2009.

Silva, F. B. R.; Riché, G. R.; Tonneau, J. P.; Sousa Neto, N. C.; Brito, L. T. L.; Coreia, R. C.; Cavalcanti, A. C.; Silva, F. H. B. B.; Silva, A. B.; Araújo Filho, J. C. Zoneamento agroecológico do Nordeste: Diagnóstico do quadro natural e agrossocioeconômico. Petrolina: Embrapa CPATSA; Recife: Embrapa CNPS; Recife: UEP, 1993. 89 p. Documentos, 80

Silva, F. B. R.; Santos, J. C. P.; Silva, A. B.; Cavalcanti, A. C.; Silva, F. H. B. B.; Burgos, N.; Parahyba, R. B. V.; Oliveira Neto, M. B.; Sousa Neto, N. C.; Araújo Filho, J. C.; Lopes, O. F.; Luz, L. R. P. P.; Leite, A. P.; Souza, L. G. M. C.; Silva, C. P.; Silva, M. A. V.; Barros, A. H. C. Zoneamento agroecológico do estado de Pernambuco: Recife: Embrapa Solos - Unidade de Execução de Pesquisa e Desenvolvimento - UEP Recife, 2001. CD-Rom. Documentos, 35

Staley, D. M.; Wasklewicz, T. A.; Blaszczynski, J. S. Surficial patterns of debris flow deposition on alluvial fans in Death Valley, CA using airborne laser swath mapping Geomorphology, v.74, p.152-163, 2006. 